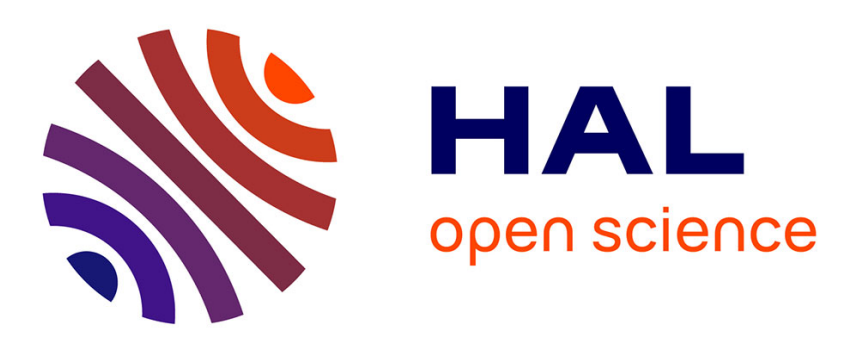

\title{
Diagnosis of a commercial PEM fuel cell stack via incomplete spectra and fuzzy clustering
}

\author{
Z. Zheng, R. Petrone, M.C. Pera, D. Hissel, M. Becherif, C. Pianese
}

\section{To cite this version:}

Z. Zheng, R. Petrone, M.C. Pera, D. Hissel, M. Becherif, et al.. Diagnosis of a commercial PEM fuel cell stack via incomplete spectra and fuzzy clustering. IECON 2013 - 39th Annual Conference of the IEEE Industrial Electronics Society, Nov 2013, Vienne, Austria. pp.1595-1600, 10.1109/IECON.2013.6699371 . hal-02496076

\section{HAL Id: hal-02496076 \\ https://hal.univ-lorraine.fr/hal-02496076}

Submitted on 13 Apr 2020

HAL is a multi-disciplinary open access archive for the deposit and dissemination of scientific research documents, whether they are published or not. The documents may come from teaching and research institutions in France or abroad, or from public or private research centers.
L'archive ouverte pluridisciplinaire HAL, est destinée au dépôt et à la diffusion de documents scientifiques de niveau recherche, publiés ou non, émanant des établissements d'enseignement et de recherche français ou étrangers, des laboratoires publics ou privés. 


\title{
Diagnosis of a Commercial PEM Fuel Cell Stack via Incomplete Spectra and Fuzzy Clustering
}

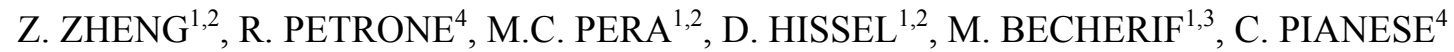 \\ ${ }^{1}$ FCLAB Research Federation, FR CNRS 3539, FEMTO-ST/Energy Department, UMR CNRS 6174, \\ ${ }^{2}$ University of Franche-Comté, 90010 Belfort Cedex, France \\ ${ }^{3}$ University of Technology of Belfort-Montbéliard, 90010 Belfort Cedex, France \\ ${ }^{4}$ Department of Industrial Engineering, University of Salerno, Via ponte don Melillo, 84084 Fisciano (SA), Italy \\ Email: zhixue.zheng@femto-st.fr
}

\begin{abstract}
To realize the commercialization of proton exchange membrane (PEM) fuel cells, durability and reliability remain big challenges. This paper aims to develop a fault detection, identification and analysis methodology based on a commercial fuel cell system. Effect of air stoichiometry is studied using electrochemical impedance spectroscopy (EIS). Relevant faults are: oxygen starvation, water flooding and drying. Based on the EIS measurements, a non-model based methodology is proposed consisting of four parts: feature extraction based on the spectra, feature selection, fuzzy clustering and fault analysis. Validity of the proposed diagnostic methodology is verified experimentally.
\end{abstract}

Keywords-fault diagnosis; PEM fuel cell stack; EIS; fuzzy clustering; oxygen starvation; flooding

\section{INTRODUCTION}

Fuel cell (FC) is a clean and efficient electro-chemical power source, as it converts directly chemical energy of the fuel (e.g. hydrogen) into electricity without internal combustion and with water and heat as only by-products [1]. Among various types of FCs, four are commercially available nowadays, including phosphoric acid, proton exchange membrane or polymer electrolyte membrane (PEM), molten carbonate and solid oxide FCs. Discriminating characteristics such as low operating temperature $\left(50\right.$ to $\left.100^{\circ} \mathrm{C}\right)$, high power density, low weight and volume, quick start-up ability make low temperature PEM fuel cell (PEMFC) as a leading candidate for transportation and some stationary applications. However, for its further commercialization, reliability and degradation over time remain the main constraints [2].

In recent years, electrochemical impedance spectroscopy (EIS) has gained a high popularity in PEMFC research area $[3,4]$. EIS is a powerful tool for characterizing different electrochemical processes in the FC: ohmic, kinetic and mass transport processes [5]. A commonly utilized method to interpret EIS data is an electrical equivalent circuit (EEC), through which parameters related to each process can be calculated and utilized for fault diagnosis. Due to the nonlinearities of the circuit components, several solutions fit the data and the identification of the parameters is challenging and can draw to wrong conclusions [5].

As for PEMFC diagnosis, both model-based and non-model based methods have been developed in recent years. Generally, in model-based methods, analytic models, grey-box, or blackbox ones are built firstly for residual generation, i.e., generation of signals which reflect the faults. A decision (whether a fault occurs and what type it is) is further made in the following residual evaluation step [2]. Non-model based methods propose an interesting alternative, especially in the case of modeling uncertainty or presence of incomplete knowledge of the system. No acquirement of mathematical or physical model, capability of fault isolation and dealing with nonlinear problems, low computational burden make them promising for real-time applications [6].

There are three main objectives within this study. The first is to obtain valid EIS measurements from a commercial PEMFC system in consideration of the effect of control board and auxiliaries and also purging. The second is to configure different operating conditions on the commercial system and study their influences. The third is to develop a non-model based diagnostic methodology dedicated to real-time application with the capability of fault detection, isolation and analysis.

This paper is organized as follows: section II is contributed to the on-line implementation of EIS on a commercial PEMFC system; in the following section, a fuzzy clustering based diagnostic methodology is proposed for identification of different stack status; a conclusion and exploration of diagnosis results are given in the final section.

\section{ON-LINE EIS IMPLEMENTATION OF NEXA ${ }^{\mathrm{TM}}$ SYSTEM}

\section{A. Introduciton of Ballard Nexa ${ }^{T M}$ system}

The Nexa ${ }^{\mathrm{TM}}$ system was introduced by Ballard company in 2001 and it is commercially available for portable and back-up power markets, in the power range of $1 \mathrm{~kW}$ [7]. The 47-cell stack provides a net power of $1.2 \mathrm{~kW}$ at nominal output of 26VDC. System's specifications are collected in Table 1.

TABLE I Nexa ${ }^{\mathrm{TM}}$ system specifications

\begin{tabular}{|c|c|c|}
\hline $\begin{array}{c}\text { Nexa } \\
\text { system }\end{array}$ & \multicolumn{2}{|c|}{ Specifications } \\
\hline FC type & \multicolumn{2}{|c|}{ PEMFC dead-end mode } \\
\hline Performance & Nominal power & $1200 \mathrm{~W}$ \\
\cline { 2 - 3 } & Voltage & $\begin{array}{c}22 \mathrm{~V}-50 \mathrm{~V} \\
\text { (nominal voltage: } \\
26 \mathrm{~V})\end{array}$ \\
\hline
\end{tabular}




\begin{tabular}{|c|c|c|}
\hline $\begin{array}{l}\text { Nexa }^{\mathrm{TM}} \\
\text { system }\end{array}$ & \multicolumn{2}{|c|}{ Specifications } \\
\hline FC type & \multicolumn{2}{|c|}{ PEMFC dead-end mode } \\
\hline \multirow[t]{2}{*}{ Performance } & Nominal power & $1200 \mathrm{~W}$ \\
\hline & Operating life & $1500 \mathrm{~h}$ \\
\hline \multirow{3}{*}{ Fuel } & Purity & $99.99 \% \mathrm{H}_{2}$ (vol) \\
\hline & Pressure & $70-1720 \mathrm{kPa}$ \\
\hline & Consumption & $<18.5$ SLPM \\
\hline \multirow{2}{*}{$\begin{array}{l}\text { Operating } \\
\text { envirionmen } \\
t\end{array}$} & $\begin{array}{l}\text { Temperature } \\
\text { range }\end{array}$ & $3^{\circ} \mathrm{C}-40^{\circ} \mathrm{C}$ \\
\hline & $\begin{array}{l}\text { Relative } \\
\text { humidity }\end{array}$ & $\begin{array}{c}0 \%-90 \% \text { (non- } \\
\text { condensing) }\end{array}$ \\
\hline
\end{tabular}

As shown in Fig. 1, pure and dry hydrogen is supplied at the FC anode side and maintained at an appropriate pressure by a pressure regulator. An air compressor is installed at the cathode side, which speed is adjusted in order to provide oxidant air required by the current demand. Before reaching the FCs, oxidant air is humidified by a humidity exchanger where water is transferred from the cathode outlet. At the base of the unit, a cooling fan is applied to blow air through vertical cooling channels of the stack.

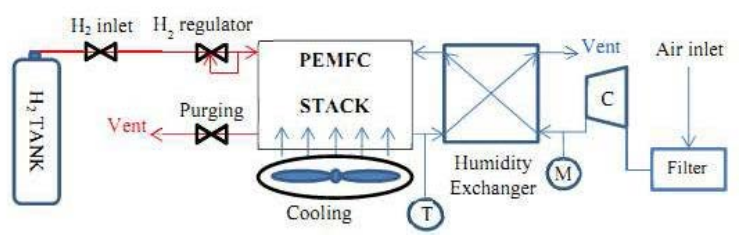

Fig. 1. The Nexa ${ }^{\mathrm{TM}}$ system schematic [8], in which $\mathrm{C}$ represents the air compressor, $\mathrm{M}$ is the air flow meter, $\mathrm{T}$ is stack temperature sensor.

\section{B. On-line EIS implementation}

EIS is an efficient tool for investigating both static and dynamical FC stack behaviors. By injecting a small sinusoidal current (voltage) with different frequencies on a static operating point, the resulting current (voltage) along with the phase angle is measured. The real and imaginary impedance are then calculated and plotted against each other, which is the so-called Nyquist plot. Impedance magnitude and phase angle can also be plotted in the Bode plot as a function of frequency.

In the Nexa ${ }^{\mathrm{TM}}$ system, the implementation of EIS is different from that performed on a stack operating in open-end mode in the laboratory test bench. Difficulties may exist in:

1) Influence of the control board. Auxiliaries such as air compressor and cooling fan are supplied and controlled by the control board, which is connected with the stack terminals. When introducing alternating current, two aspects should be taken into consideration: a). a parallel impedance is measured instead of the sole stack impedance, as shown in Fig.2; b) control signals generated on the board may introduce some noises into the measured impedance.

The proposed solution in [9] utilizes another $\mathrm{Nexa}^{\mathrm{TM}}$ system to control the electronic devices during EIS test. Thus the stack is decoupled from the rest of the system for EIS measurements. Inconveniences exist in the need and control of another system and also the switch from the two systems. In this paper, an adjustable DC voltage source is applied to supply the control board and the auxiliaries during the running state of the stack.

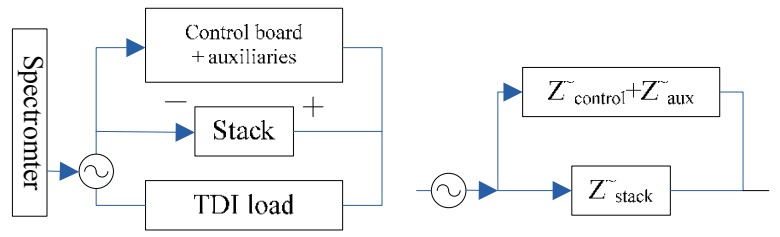

Fig. 2 Influence of control board and auxilliaries

2) Purging effect. As for commercial stack, purging effect is one of the unavoidable considerations. During the FC operation, oxidant air supplied to the cathode is depleted of oxygen and remains mainly nitrogen. Nitrogen, together with the produced water in the air stream slowly migrates across the membrane and gradually accumulates in the hydrogen stream, which results in performance decrease of certain key-cells called "purge cells" (often terminal cells)[7]. In light of this, a hydrogen purge valve is installed at the stack outlet which is periodically opened to flush out the inert gases and water and restore the performance, as it can be observed in Fig. 3.

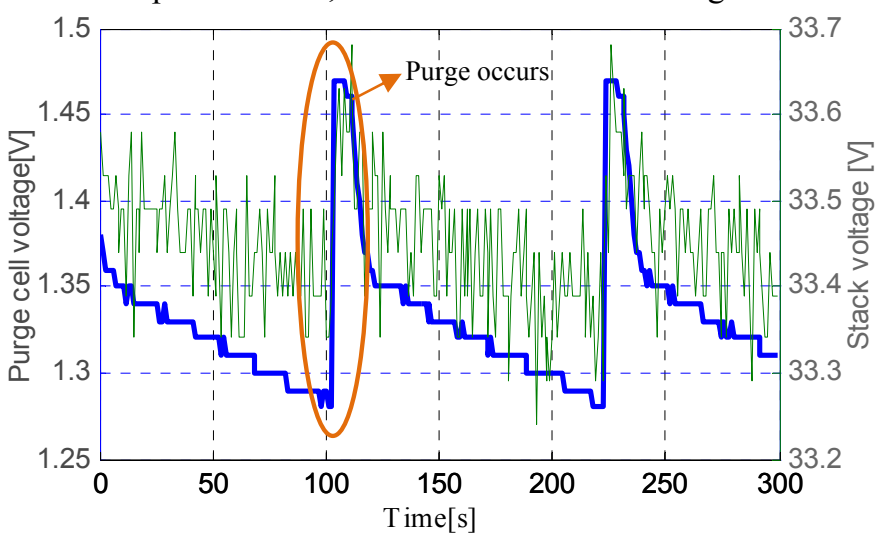

Fig. 3 Purge cell voltage and stack voltage at $I_{\text {stk }}=15 \mathrm{~A}$.

To perform EIS, fundamental conditions such as linearity and stability should be satisfied. When purge occurs, a sudden increase (about $0.2 \mathrm{~V}$ ) of purge cell voltage can be observed which may influence the stability of the EIS measurements. After further tests and analysis, it was found that purge cells are located only in the last 3 to 4 cells in the stack, purging effect is almost negligible for the 47-cell stack characterization $(0.2 \mathrm{~V} / 33.5 \mathrm{~V})$. More details about the system configurations can be found in [8].

\section{Configuration of operating conditions}

In order to perform fault diagnosis based on a non-model based methodology, different health status is collected in a first step. In the Nexa ${ }^{\mathrm{TM}}$ system, operating conditions that may influence the health status of the stack consist of: stack temperature, cathode/ anode relative humidity, cathode/anode pressure, $\mathrm{H}_{2} /$ air stoichiometry $\left(\lambda_{\text {air }}\right)$.

1) Stack temperature. The Nexa ${ }^{\mathrm{TM}}$ system is an air-cooled system, in which the temperature is not actively controlled. As 
long as the temperature is less than $65^{\circ} \mathrm{C}$, the cooling fan runs at $35 \%$ of its nominal load [7]. Once the temperature exceeds $65^{\circ} \mathrm{C}$, the speed of cooling fun is increased to maintain it at $65^{\circ} \mathrm{C}$.

2) Cathodelanode relative humidity. As mentioned in the former part, only the air part is humidified and it is done by the water produced at the cathode. To change these two factors, external humidification system should be added.

3) Cathode/anode pressure. As for $\mathrm{H}_{2}$ flow, it is supplied in dead-end mode, i.e. without outlet. $\mathrm{H}_{2}$ pressure is maintained constant (about 9.5 bar in the anode inlet) and cannot be adjusted. The cathode side is supplied by oxidant air with a normal atmospheric pressure. In the configured system, these two factors are hard to change.

3) $\mathrm{H}_{2}$ / air stoichiometry. The supply of the oxidant air is proportional to the stack current $\left(\mathrm{I}_{\text {stk }}\right)$. A possible configuration is to control the value of the stack current sensor by putting the sensor on an external adjustable current source. Air flow can be thus adjusted actively and as well as the air stoichiometry.

Based on the above analysis, our current research focuses on control of the $\lambda_{\text {air. }}$ A relationship between the air flow fair and $\lambda_{\text {air }}$ is given by [10]:

$$
\lambda_{\text {air }}=f_{\text {air }} /\left(3.57 * 10^{-7 *} I_{\mathrm{stk}} * n_{\mathrm{c}}\right) / 5.1 * 10^{4}
$$

where $\mathrm{I}_{\text {stk }}$ is the measured stack current value, $n_{\mathrm{c}}$ is the number of cells, $f_{\text {air }}$ is expressed in the unit of slpm (standard liter per minute).

At a given operating current, air flow consumed by the reaction is constant. Current measure is put on an external current source, whose value is adjusted. As the measured $I_{\text {stk }}$ is regulated, corresponding air flow changes and $\lambda_{\text {air }}$ could be configured as different values.

For the Nexa ${ }^{\mathrm{TM}}$ system, the maximum $f_{\text {air }}$ is limited to 90 slpm, corresponding $\lambda_{\text {air }}$ can be thus calculated. Furthermore, the minimal $\lambda_{\text {air }}$ should be around 2 [10]. Operating range of $\lambda_{\text {air }}$ at different stack currents are shown in Fig. 4.

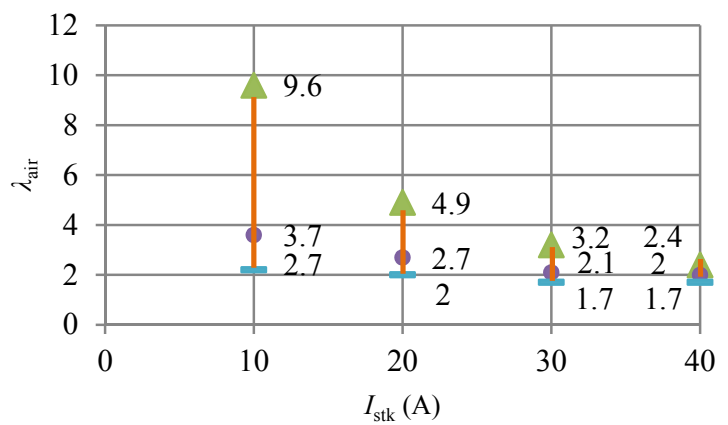

Fig.4 Operating range of air stoichiometry $\left(\lambda_{\text {air }}\right)$

\section{Effect of air stoichiometry}

The air stoichiometry ( $\left.\lambda_{\text {air }}\right)$ plays an important role in the performance of PEMFC stack. It influences the oxygen availability as well as the humidity of the membrane [11]. A low $\lambda_{\text {air }}$ limits the availability of oxygen which participates into the oxygen reduction reaction at the cathode. A low $\lambda_{\text {air }}$ can also reduce the water removal rate and may cause cathode flooding, which further limits the oxygen availability [11]. On the other side, a high $\lambda_{\text {air }}$ increases the oxygen supply at the cathode and in this sense improves the FC performance. However, water removal rate will be accelerated and membrane drying may be caused. The high $\lambda_{\text {air }}$ is beneficial to the FC health status if the positive effect of increased oxygen availability overcomes the negative effect of high water removal rate. To summarize, Table 2 is listed.

Table II Effects of air stoichiometry

\begin{tabular}{|l|l|l|}
\hline $\begin{array}{l}\text { Operating } \\
\text { conditions }\end{array}$ & Influences & Possible effects \\
\hline$\lambda_{\text {air }} \boldsymbol{\uparrow}$ & Water removal rate $\mathbf{\uparrow}$ & Membrane drying \\
& $\mathrm{O}_{2}$ availability $\uparrow$ & Higher performance \\
\hline$\lambda_{\text {air }} \downarrow$ & Water removal rate $\downarrow$ & Cathode flooding \\
& $\mathrm{O}_{2}$ availability $\downarrow$ & $\mathrm{O}_{2}$ starvation \\
\hline
\end{tabular}

In most of recent studies, effect of $\lambda_{\text {air }}$ has been mainly focused on static or dynamic FC performance by analyzing the evolution of polarization curves $[11,12]$. Our study could be very interesting since the influence of $\lambda_{\text {air }}$ under low and high stack current is researched using EIS as an efficient tool.

EIS is performed on the commercial $\mathrm{Nexa}^{\mathrm{TM}}$ system in the galvanostatic node with AC excitation current $\left(i_{\mathrm{ac}}\right) 5 \%$ of $\mathrm{I}_{\mathrm{stk}}$, in the frequency range of $1 \mathrm{kHz}-0.1 \mathrm{~Hz}$. Test bench developed in the laboratory consists of six parts: (1) Nexa ${ }^{\mathrm{TM}}$ System, (2) PC for system monitoring, (3) Electrical load (TDI Dynaload RBL 100-300-2000), (4) Home-made spectrometer, (5) Adjustable $\mathrm{V}_{\mathrm{DC}}$ power supply (elc $-\mathrm{AL936N}$ ) and (6)Adjustable $\mathrm{I}_{\mathrm{DC}}$ power supply (CNB7).

\section{1) Effect of $\lambda_{\text {air }}$ at low stack current $\left(I_{\text {stk }}=10 \mathrm{~A}\right)$}

At low current density, membrane humidity is maintained at a relative low level due to insufficient water produced at the cathode. In this case, a high $\lambda_{\text {air }}$ is prone to causing membrane drying. Fig. 5 plotted the spectra obtained under different $\lambda_{\text {air }}$ configured according to Table 3. Considering the system's security, the maximal $\lambda_{\text {air }}$ configured is slightly smaller than the maximal value shown in Fig. 4.

Table III Configuration of $\lambda$ air at $\mathrm{I}_{\text {stk }}=10 \mathrm{~A}$

\begin{tabular}{|l|c|c|c|c|c|c|c|c|}
\hline Configuration & \multicolumn{2}{|c|}{ Low $\lambda_{\text {air }}$} & Normal & \multicolumn{5}{|c|}{ High $\lambda_{\text {air }}$} \\
\hline$\lambda_{\text {air }}$ & 2.7 & 3.2 & 3.7 & 4.7 & 5.7 & 6.9 & 7.9 & 9.3 \\
\hline
\end{tabular}

When $\lambda_{\text {air }}$ is less than the normal value $\left(\lambda_{\text {air }}=3.7\right)$, low frequency loop becomes larger and more fluctuations exist in the data points, which indicates a difficult mass transport. As summarized in Table 2, this could be either caused by cathode flooding or $\mathrm{O}_{2}$ starvation in the FC. As $\lambda_{\text {air }}$ increases, difficult mass transport disappears, spectra become much compacter and smoother, and perfect semicircles appear when $\lambda_{\text {air }}>4.7$. As mentioned in the former part, a side-effect of high $\lambda_{\text {air }}$ is membrane drying resulting from a low water removal rate. However, it can be observed in the enlarged figure that no obvious differences exist in the high frequency part which 
represent the charge transfer process (in order to observe the phenomenon more clearly, makers in the enlarged figure are removed). Thus the high $\lambda_{\text {air }}$ configured within the operating range of $\mathrm{Nexa}^{\mathrm{TM}}$ has no negative effect on the FC performance.

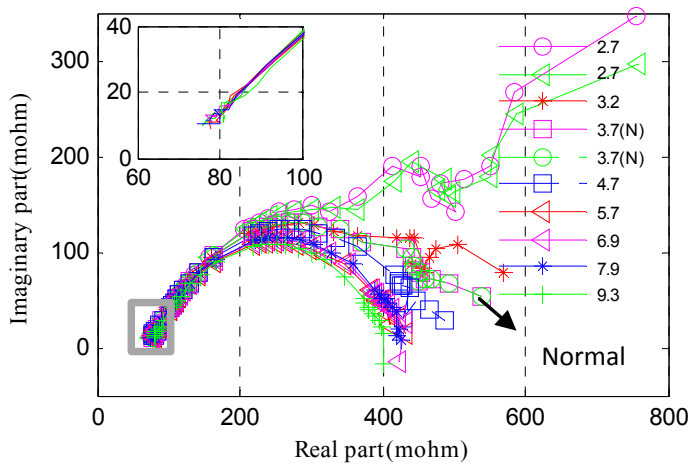

Fig. 5. Nyquist plot at $\mathrm{I}_{\text {stk }}=10 \mathrm{~A}$

\section{2) Effect of $\lambda_{\text {air }}$ at high stack current $\left(I_{\text {stk }}=30 \mathrm{~A}\right)$}

At high current density, water produced by the oxygen reduction reaction makes the membrane humidity maintained a relative high level. A low $\lambda_{\text {air }}$ in this case has a risk of causing water flooding in the $\mathrm{FC}$ due to the low water removal rate. The values of $\lambda_{\text {air }}$ are configured in Table 4 and corresponding spectra are plotted in Fig. 6.

Table IV Configuration of $\lambda$ air at Istk $=30 \mathrm{~A}$

\begin{tabular}{|c|c|c|c|c|c|}
\hline Configuration & \multicolumn{2}{|c|}{ Low $\lambda_{\text {air }}$} & normal & \multicolumn{2}{c|}{ High $\lambda_{\text {air }}$} \\
\hline$\lambda_{\text {air }}$ & 1.7 & 1.9 & 2.1 & 2.5 & 3 \\
\hline
\end{tabular}

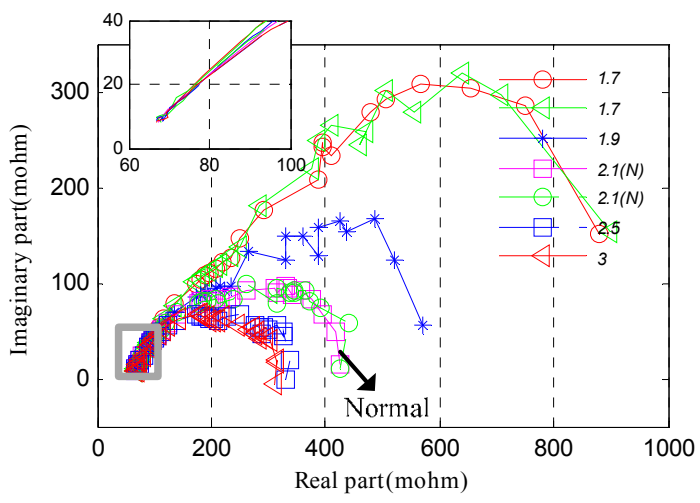

Fig. 6. Nyquist plot at $I_{\text {stk }}=30 \mathrm{~A}$

Compared with Fig. 5, internal resistance (intercept of the spectrum with the real axis at low frequency) of the stack at $I_{\text {stk }}=30 \mathrm{~A}$ is smaller as seen in the enlarged figure of Fig. 6 . This is mainly due to the higher humidity level of the membrane. As $\lambda_{\text {air }}$ decreases from its normal value $\left(\lambda_{\text {air }}=2.1\right)$, diameter of the spectra loops increases. However, whether the difficult mass transport herein is resulted from low $\lambda_{\text {air }}$ caused low oxygen starvation or from flooding caused starvation, further experiments need to be performed. As $\lambda_{\text {air }}$ increases, more contractive and smoother spectra can be observed, which indicate a positive effect of the high $\lambda_{\text {air. }}$.

\section{FAULT DIAGNOSIS BASED ON FUZZY CLUSTERING}

The overall concept of fault diagnosis consists in three following tasks: fault detection (the occurrence of faults), fault isolation (localization/classification of different faults), and fault analysis or identification (type determination, cause or magnitude of the fault). In view of this, a fault diagnosis system according to its performance, can further be classified into FD (fault detection), FDI (fault detection and isolation), and also FDIA (fault diagnosis, isolation and analysis) [13].

In this study, a non-model based FDIA system applying fuzzy clustering combined with expertise knowledge is developed.

\section{A. Principle of fuzzy c-means clustering}

As an important unsupervised partitioning algorithm, fuzzy-c means (FCM) clustering has been extensively studied in many applications, such as pattern recognition, machine learning and data mining [14]. The main idea is grouping a set of data into clusters such that data in the same cluster have a high degree of similarity, while those belonging to different clusters possess a high degree of dissimilarity.

Consider a set of $\mathrm{N}$ data points denoted by $X=\left[x_{1, \ldots,}, x_{\mathrm{N}}\right]^{\prime}$ to be allocated into $c$ clusters with cluster centers represented as $V=\left[v_{1}, \ldots, v_{\mathrm{c}}\right]^{\prime}$. Let $U=\left[\mu_{i k}\right] \quad(i=1, \ldots, c) \quad(\mathrm{k}=1, \ldots, \mathrm{N})$ be a membership matrix where $\mu_{i k}$ is the membership degree of a given point $x_{k}$ belonging to cluster $i$. $\mu_{i k}$ should be subjected to the following restrictions :

1) $\mu_{i k} \epsilon[0,1]$ for all $i$ and $k$;

2) $0<\sum_{k=1}^{N} \mu_{i k}<N$ for all $i$;

3) $\sum_{i=1}^{c} \mu_{i k}=1$ for all $k$.

FCM aims to find the clusters underlying the data points and also the fuzzy partition matrix $U$ by minimizing an objective function given by:

$$
J(X ; U, V)=\sum_{i=1}^{c} \sum_{k=1}^{N} \mu_{i k}^{m}\left\|x_{k}-v_{i}\right\|^{2}
$$

where $\left\|x_{k}-v_{i}\right\|^{2}=\left(x_{k}-v_{i}\right)^{T}\left(x_{k}-v_{i}\right)=D_{i k}$ is the standard Euclidean distance norm, $m$ is the fuzziness index, with a commonly adopted value of 2 .

An iterative optimization of the objective function is carried out, with the update of membership degree $\mu_{\mathrm{ik}}$ and cluster centers $v_{\mathrm{i}}$ given by:

$$
\begin{gathered}
\mu_{i k}=\frac{1}{\sum_{j=1}^{c}\left(D_{i k} / D_{j k}\right)^{2 /(m-1)}}, 1 \leq i \leq c, 1 \leq k \leq N \\
v_{i}=\frac{\sum_{k=1}^{N} \mu_{i k}^{m} x_{k}}{\sum_{k=1}^{N} \mu_{i k}^{m}}, 1 \leq i \leq c
\end{gathered}
$$

The FCM algorithm is iterated until the value of the objective function no longer decreases or remains within a given threshold [15].

\section{B. Feature extraction and selection}

To perform fuzzy clustering, discriminating features that reflect the stack health status are essential. According to the 
literature, relevant features in a spectrum characterizing health status of the stack include:

1) Internal resistance, mainly the membrane resistance [16], which is the high-frequency intercept of the impedance arc. A high value indicates insufficient humidification of the membrane.

2) Polarization resistance [17], which is the impedance when the frequency approaches zero, reflects the global performance in quasi-static operating conditions.

3) Difference of the polarization and internal resistance, which is in fact the width of the impedance spectrum in the real part axis, is subject to degradation resulting from a loss of mass transport rate of reactants inside the stack [2].

4) The maximal absolute phase value of the impedance [2], which reflects degradation of the electrolyte membrane, shows important variances during the degradation.

Additionally, maximal magnitude and occurring frequency of maximal phase value are also included as discriminating features based on an initial observation of the bode plot.

However, it can be observed in Fig. 5 and Fig. 6 that most of the acquired spectra are incomplete, which means that features like internal resistance and polarization resistance cannot be extracted directly (especially under low $\lambda_{\text {air }}$ conditions). Three solutions are taken into consideration:

1)Extending the frequency range. This could be much more time consuming with acquirement of each spectrum taking more than 30 minutes or even 1 hour. Additionally, impedance at low frequencies $(\mathrm{f}<2 \mathrm{~Hz}$ ) already shows some disturbances, which suggest being not meaningful to collect more points.

2)Extrapolation of the spectra. Through curve fitting methods, e.g. polynomial fitting, the spectrum to the real axis can be extended. Internal resistance can hereby be obtained. However, there exist some spectrum, e.g. spectrum at $\lambda_{\text {air }}=2.7$ in Fig. 7 cannot be collected in this way.

3) Choosing valuable features based on the incomplete spectra. According to our former research on two datasets acquired from two different PEMFC systems, occurring frequency of the maximal phase and difference of the two resistances are selected as valuable features [15], with the objectve of monitoring water behavior in the stack. At the same time, a high correlation between difference of the two resistances and maximal magnitude is observed. Inspired by this, the whole spectrum may not be essential for feature extracion. If this is true, a more time-saving implementaion of EIS with only several key frequency components is highly expected for further real-time diagnosis.

Based on the feature extracted in the former step, feature selection is performed. The basic task of feature selection consists of two aspects: selecting the most relevant features to the target faults and reducing redundant information contained in the features. In response to this, an automatic feature selection procedure consisting of two parts-variance analysis and correlation coefficient (CC) analysis is developed (for further details see [15]).

\section{Diagnosis results}

Through the feature-selection procedure, two features are selected: occurring frequency of maximal phase and maximal magnitude, which are identical to our former study on two other PEMFC systems. Fuzzy clustering is then performed on the constructed two-dimensional feature space. Data points representing different operating conditions are classified into three clusters, as shown in Fig. 7 and Fig. 8.

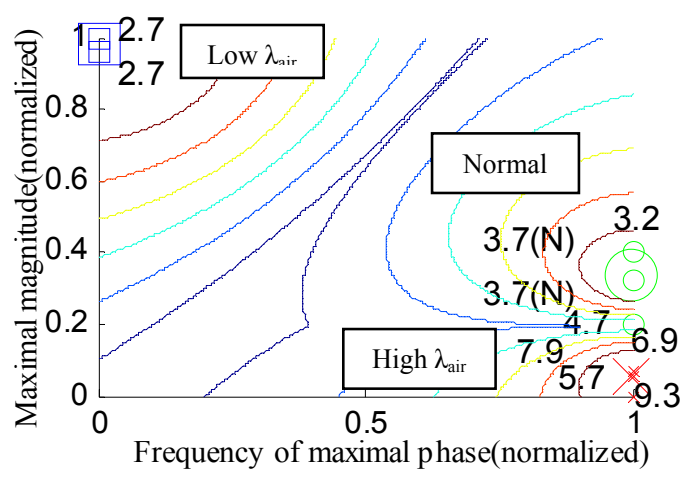

Fig. 7. Fuzzy clustering results at $\mathrm{I}_{\mathrm{stk}}=10 \mathrm{~A}, \lambda_{\text {air }}=2.7-9.3$

As shown in Fig. 7, three clusters represent low airstoichiometry conditions $\left(\lambda_{\text {air }}=2.7\right)$, normal conditions $\left(\lambda_{\text {air }}=3.2\right.$, $3.7,4.7)$, and high air-stoichiometry conditions $\left(\lambda_{\text {air }}=5.7,6.9\right.$, $7.9,9.3)$, respectively. Furthermore, the cluster dedicated to the characterization of low $\lambda_{\text {air }}$ is much more separated from the rest two which are closed to each other. Considering the effect of $\lambda_{\text {air }}$, the low $\lambda_{\text {air }}$ one is in fact a reflection of difficult mass transfer which is caused either by oxygen starvation or water flooding. The rest two can be actually further integrated into one cluster with high membership degrees $(>0.98)$ of each data points belonging to the corresponding cluster center, as shown in Fig. 8. From the perspective of fault diagnosis, the obtained clusters can be further labeled as: oxygen starvation/flooding, and normal status.

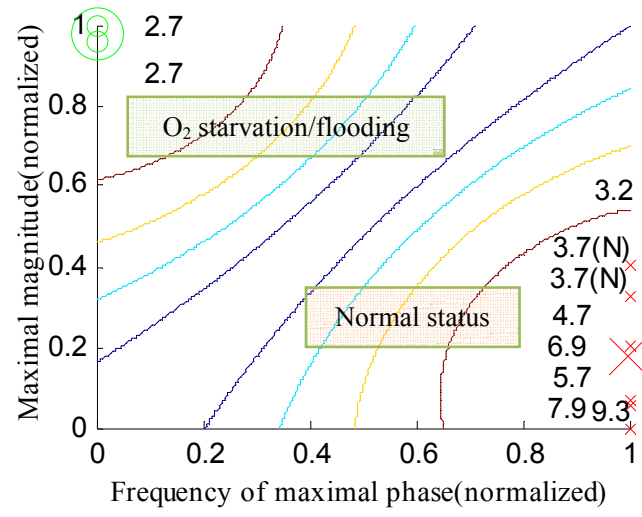

Fig. 8. Fuzzy clustering results corresponding to fault diagnosis

Compared to the clusters obtained at low current as shown in Fig. 7, the three clusters obtained in Fig. 9 are better discriminated, representing low $\lambda_{\text {air }}$ conditions $\left(\lambda_{\text {air }}=1.7\right)$, normal conditions $\left(\lambda_{\text {air }}=1.9\right.$ and 2.1$)$, and high $\lambda_{\text {air }}$ conditions $\left(\lambda_{\text {air }}=2.5\right.$ and 3). According to former analysis on effect of $\lambda_{\text {air, }}$ each cluster can be labeled respectively: oxygen 
starvation/flooding, normal status, and healthier status. The reason why a healthier status is added here is that the normal operating conditions set by the company (since it is a commercial system) are not necessarily (or always) the optimal ones. This may provide some references or improvements on further system design.

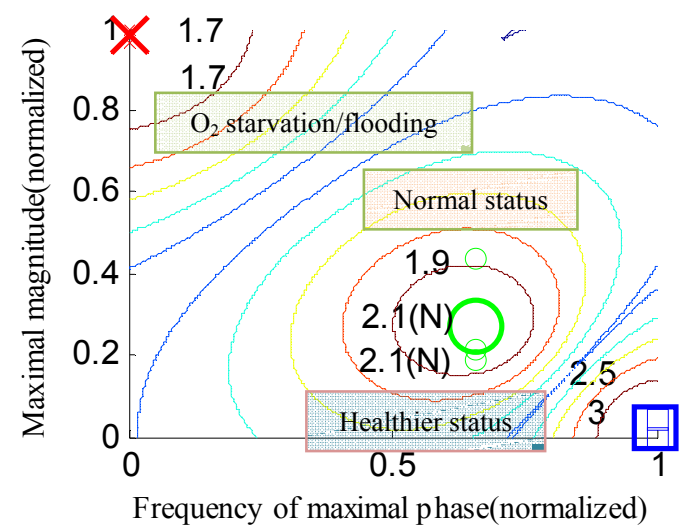

Fig. 9. Fuzzy clustering results at $\mathrm{I}_{\mathrm{stk}}=30 \mathrm{~A}, \lambda_{\text {air }}=1.7-3$

\section{Results and Discussion}

As presented in the former part, the proposed methodology is able to detect and isolate the health status of a PEMFC stack. Especially, the effect of air stoichiometry on a commercial PEMFC system is studied. The successfully performed fault diagnosis may provide some useful inspirations for further research. First, the two selected features-maximal magnitude and occurring frequency of maximal phase are proven to be valuable for health monitoring of the stack. The utilization of the two features brings some convenience such as no acquirements of the whole spectra and easiness for performing fuzzy clustering. Second, the results obtained may provide some references for the design of system operating condition. Finally, the proposed methodology is highly expected to be further realized for real-time diagnosis as its ability for fault detection, isolation and analysis, and also small computational burden.

\section{CONCLUSION}

As a promising power conversion device, PEMFCs have received considerable attentions in recent years. To realize the commercialization of PEMFCs, durability and reliability remain large challenges. A commercial Ballard Nexa ${ }^{\mathrm{TM}}$ system is studied in this paper, with the purpose of studying the effects of different operating conditions (especially $\lambda_{\text {air }}$ ) and developing a non-model based diagnostic methodology for real-time applications. A fuzzy clustering based FDIA system combined expertise knowledge is established using the sole EIS measurements as database. During the feature-extraction and selection step, two features are considered as valuable ones: maximal magnitude and occurring frequency of maximal phase. Based on the constructed two-dimensional feature space, different operating conditions are successfully classified and labeled as: oxygen starvation/flooding, normal status and healthier status (high current case). Experiment results can be further exploited in the following ways. First, research the versatility of the selected two features for other fault types and different PEMFC systems. Second, diagnosis results may be utilized as a reference for system design. Finally, the developed diagnostic methodology will be further applied for real-time application within the framework of an European project.

\section{ACKNOWLEDGMENT}

The work performed was done within the European DCODE project, funded under Grant Agreement 256673 of the Fuel Cells and Hydrogen Joint Technology Initiative. And we'd like to thank Xavier Francois and Fabien Harel from IFSTTAR for their kind assistance during the experiments.

\section{REFERENCES}

[1] N. Yousfi Steiner, D. Hissel, P. Moçotéguy, and D. Candusso, "Diagnosis of polymer electrolyte fuel cells failure modes (flooding \& drying out) by neural networks modeling “, Int. J. Hydrog. Energy, vol. 36, no 4, pp. 3067-3075, February. 2011.

[2] D. Hissel, D. Candusso, and F. H. Harel, " Fuzzy-Clustering Durability Diagnosis of Polymer Electrolyte Fuel Cells Dedicated to Transportation Applications ", IEEE Trans. Veh. Technol., vol. 4, no 5, pp. 1211-2420, Sept. 2007.

[3] R. Onanena, L. Oukhellou, D. Candusso, et al., "Fuel cells static and dynamic characterizations as tools for the estimation of their ageing time ”, Int. J. Hydrog. Energy, vol. 33, pp. 2-11, 2010.

[4] N. Fouquet, C. Doulet, C. Nouillant, et al., " Model based PEM fuel cell state-of-health monitoring via ac impedance measurements", J. Power Sources, vol. 159, no 2, pp. 905-913, Sept. 2006.

[5] X. Yuan, J. Colin, M. Blanco, et al., "AC impedance diagnosis of a 500 W PEM fuel cell stack Part I: Stack impedance “, J. Power Sources, vol. 161, pp. 920-928, 2006.

[6] Z. Zheng, R. Petrone, M.C.Péra, et al., , "A review on non-model based diagnosis methodologies for PEM fuel cell stacks and systems", International Journal of Hydrogen Energy, unpublished.

[7] Nexa ${ }^{\mathrm{TM}}$ power module user's manual, Ballard Power Systems Inc. , June 2003.

[8] R. Petrone, Z.Zheng, D. Hissel et al., "Implementation of EIS measurements on an embedded commercial system", in $5^{\text {th }}$ international conference on fundamental \& development of fuel cells, April 2013.

[9] W. Zhu, R.Payne, D.Cahela et al., "In-Situ Assessment of PEM Fuel Cells via AC Impedance at Operational Loads", unpublished.

[10] J. Larminie and A. Dicks, Fuel Cell Systems Explained, 2nd edition. Wiley, 2003.

[11] Q. Yan, H. Toghiani, and H. Causey, "Steady state and dynamic performance of proton exchange membrane fuel cells (PEMFCs) under various operating conditions and load changes “, J. Power Sources, vol. 161, n 1 , pp. 492-502, 2006.

[12] M. Pérez-Page and V. Pérez-Herranz, "Effect of the Operation and Humidification Temperatures on the Performance of a PEM Fuel Cell Stack", Ecs Trans., vol. 25, no 1, pp. 733-745, sept. 2009.

[13] S. X. Ding, Model-based Fault Diagnosis Techniques, vol. 22. SpringerVerlag, 2008.

[14] B. A. Pimentel and R. M. C. R. de Souza, “A multivariate fuzzy cmeans method ", Appl. Soft Comput., vol. 13, n 4, pp. 1592-1607, April. 2013.

[15] Z. Zheng, M.C.Péra, D. Hissel and M. Becherif, "Diagnosis of proton exchange membrane fuel cell (PEMFC) stack based on fuzzy clustering", in $5^{\text {th }}$ international conference on fundamental \& development of fuel cells, April 2013.

[16] X.Yuan, J. C.Sun, H.Wang, and J.Zhang, "AC impedance diagnosis of a 500W PEM fuel cell stack Part II: Individual cell impedance “, J. Power Sources, vol. 161, no 2, pp. 929-937, 2006.

[17] S.Asghari, A.Mokmeli, and M.Samavati, "Study of PEM fuel cell performance by electrochemical impedance spectroscopy", Int. J. Hydrog. Energy, vol. 35, no 17, pp. 9283-9290, 2010. 